\title{
A grounded theory como abordagem metodológica para pesquisas qualitativas em odontologia
}

\author{
The grounded theory as a methodological approach \\ for qualitative research in dentistry
}

Lucélia Silva Nico ${ }^{1}$

Silvia Cristina M angini Bocchi ${ }^{2}$

Tânia Ruiz ${ }^{1}$

Rafael daSilveira M oreira ${ }^{1}$

${ }^{1}$ Departamento deSaúde

Pública. Faculdadede

M edicina de Botucatu.

UniversidadeEstadual

Paulista - UNESP.

Secretaria de Pós-

Graduação. Distrito de

Rubião Júnior, s/n. Caixa

Postal 549 18618-970

Botucatu SP.

luceliasn@ig.com.br

${ }^{2}$ Departamento de

Enfermagem. Faculdade de

Medicina deBotucatu.

Universidade Estadual

Paulista - UNESP.
Abstract This study proposes the use of a methodological approach in Dentistry that is also deployed in qualitative research: Grounded theory. The proposal is to use it whenever the intention is to understand phenomena or describe them from a subjective standpoint. Researchers are using the qualitative approach more and more often in health studies, and, in Dentistry, a methodological approach such as this has become essential in order to explore subjects that have not yet been addressed through this methodological approach, endowing studies with original contributions and improving knowledge. The steps to be followed are presented and illustrated by some examples drawn from interviews conducted during a study aimed at understanding the experience of older persons with regard to oral health during their life spans, in parallel to the development and validation of a theoretical model that is representative of such experience. Key words Grounded theory, Qualitative research, Oral health, Symbolic interactionism
Resumo Este trabalho consiste na proposta de utilização, em 0 dontologia, de uma abordagem metodológica usada em pesquisasqualitativas, de nominada Grounded Theory, quando se objetiva compreender fenômenos ou se pretende descrevêlos de acordo com o ponto de vista do sujeito. Pesquisas em saúde, utilizando abordagens qualitativas, estão sendo, cada vez mais, empregadas entre pesquisadores e, na O dontologia, esta abordagem metodológica proposta torna-sefundamental, no sentido de propiciar a exploração de assuntos ainda pouco trabalhados nesta perspectiva metodológica, possibilitando que as pesquisas adquiriram contribuições originais e, assim, ampliando nosso conhecimento. São apresentadas as etapas a serem seguidas nesta abordagem, elucidando-as com al guns exemplos de parte de entrevistas realizadas numa pesquisa que teve como objetivos: compreender a experiência do idoso com a saúde bucal ao longo da vida e desenvolver e validar um modelo teórico representativo dessa experiência.

Palavras-chave Grounded theory, Pesquisa qualitativa, Saúde bucal, Interacionismo simbólico 


\section{Introdução}

A Grounded Theory consiste numa abordagem metodológica utilizada na pesquisa qualitativa, tendo como significado "Teoria Fundamentada em Dados", quando traduzida para a língua portuguesa. A Grounded Theory tem suas origens interacionistas e, dessa forma, o Interacionismo Simbólico é o referencial teórico muitas vezes adotado quando pesquisas nesta abordagem são utilizadas.

Para Charon ${ }^{1}$, o Interacionismo Simbólico baseia-se numa perspectiva da Psicologia Social, especialmente relevante para as preocupações da Sociologia. Ao invés de se focar no indivíduo e suas características de personalidade, ou como a estrutura social ou a situação social influencia o comportamento individual, o Interacionismo Simbólico focaliza-se sobre a natureza da interação, nas atividades sociais dinâmicas tomadas entre as pessoas.

Bazilli et al. ${ }^{2}$ afirmam queas origens einfluências da Psicologia Social referem-seàs idéias acerca do social edo individual, queexistiram no final do século XIX einício do século XX. Estes autores afirmam que: a psicanálise, as teorias de cortecognitivista, o behaviorismo e as teorias derivadas da Antropologia e da Sociologia política dão sua versão da relação indivíduo-sociedade, das suas resultantes e implicações para o psiquismo humano².

Bazilli et al. ${ }^{2}$ expõem que cada um destes enfoques propõe um objeto, um recorte epistemológico ou metodológico para compreender o que cada enfoque mencionado considera essencial para a: Psicologia social, a Psicologia do social eas Psicossociologias. Prosseguem ainda afirmando que o Interacionismo Simbólico emergiu deste contexto de idéias presentes no final do século $X I X$ einício do século XX, na tentativa de contribuir para a discussão e conceito da Psicologia do Social.

Embora seja um equívoco atribuir todas as idéias básicas no Interacionismo Simbólico a uma única pessoa, George H erbert M ead (1863-1931) foi, indubitavelmente, o gerador primordial do movimento. Nesse sentido, M ead pode ser chamado o "pai" do Interacionismo Simbólico ${ }^{3}$.

No entanto, M ead jamais utilizou a expressão Interacionismo Simbólico. Quem a criou foi Blumer, um de seus seguidores, em 1937, responsável por compilar as idéias de seu mestre. Assim, nomeou uma abordagem, relativamente distinta, para o estudo da vida e ação humana em grupo ${ }^{3}$.

Charon ${ }^{1}$ afirma que o Interacionismo Simbólico cria uma imagem ativa maior do ser hu- mano e rejeita a imagem do indivíduo passivo. Osindivíduosinteragem eas sociedades são constituídas de indivíduos interagindo.

Para este autor, o ser humano é compreendido como um ser agindo no presente, influenciado não somente pelo que aconteceu no passado, mas pelo queestá acontecendo agora. A interação acontece neste momento: 0 que fazemos agora está ligado a essa interação. Esta interação não é somente o que está acontecen do entre pessoas, mas também o que acontece dentro dos indivíduos. Os seres humanos atuam em um mundo que eles definem. Agimos de acordo com o modo que definimos a situação em que estamos vivenciando. Embora essa definição possa ser influenciada por aqueles com quem interagimos, ela étambém resultado de nossa própria definição, nossa interpretação da situação.

No Interacionismo Simbólico, também há a idéia que todos nós definimos o mundo em que agimos e parte dessa definição é nossa. Envolve escolher consciente a direção de nossas ações em face dessa definição, a identificação dessas açõese a de outros e a nossa própria redireção ${ }^{1}$.

Assim, esses dois referenciais (Grounded The ory como o referencial metodológico elnteracionismo Simbólico como referencial teórico) podem ser utilizados em pesquisas qualitativas.

\section{Definindo pesquisa qualitativa}

Strauss \& Corbin ${ }^{4}$ afirmam que o significado do termo pesquisa qualitativa consiste na pesquisa que produz resultados não provenientes de procedimentos estatísticos, referindo aos estudos sobreavidado indivíduo, experiências devida, comportamentos e emoções. Também quanto ao funcionamento organizacional, movimentos sociais, fenômeno cultural einteração entre nações.

0 termo pesquisa qualitativa ainda é confuso, possuindo diferentes significados para as pessoas. Estes autores citam o exemplo de pesquisadores que reúnem dados dos significados das entrevistas e das observações, sen do técnicas normalmente associadas com métodos qualitativos. Porém, eles codificam os dados de um modo que os permitem ser analisados estatisticamente. Estes pesquisadores estão, na verdade, quantificando dados qualitativos. É sabido que alguns dados podem ser quantificados com bom senso ou desde que sejam informações preliminares sobre pessoas ou objetos. A importância se configura, entretanto, quanto à análiseinterpretativa dos resultados, devendo ser a parte fundamental do estudo ${ }^{4}$. 
Quando aplicamos um questionário, mesmo que de aspectos aparentemente subjetivos, quantificando resultados em contraposição à utilização de uma abordagem metodológica interpretativa que melhor compreenda os fenômenos do estudo, não se pode considerar que estamos realizando uma pesquisa qualitativa.

Q uando Strauss \& Corbin 4 falam em quantificação nas análises qualitativas, estão, na verdade, referindo-se ao processo não matemático de interpretação, sustentado pelo propósito de descobrir conceitos erelações nos dados brutos, para organizar estes dados num esquema teórico explanatório. Estes dados podem consistir de entrevistas eobservações, podendo incluir documentos, filmes ou fitas.

Resumidamente, os autores propõem que a pesquisa qual itativa deve apresentar três componentes:

1ํ) Os dados, que podem vir de várias fontes, tais como das entrevistas, observações, documentos, fitas efilmes;

2) Os procedimentos que os pesqui sadores podem usar para interpretar e organizar os dados. Normalmente, estes procedimentos consistem na redução e nos conceitos dos dados, el aborando categorias, nos termos de suas propriedades e dimensões, e relacionando estes procedimentos por meio de uma série de declarações;

3) As informações escritas e verbais, constituindo o terceiro componente. Estas informações podem estar nos artigos científicos, nas conferências ou nos livros.

Field \& M orse ${ }^{5}$ recomendam o uso de métodos qualitativos quando se tem pouco conhecimento sobre um fenômeno ou se pretende descrevê-lo de acordo com o ponto de vista do sujeito. As abordagens qualitativas são consideradas indutivas, hipóteses e teorias emergindo durante o procedimento de coleta e análise dos dados, em que o pesquisador os examina buscando descrições, padrões e relações supostas do fenômeno e então retorna ao campo para obter mais dados e testar a hipótese. Dessa forma, a teoria vai sendo construída passo a passo, ajustando-se ao contexto da pesquisa e sendo relevante somente para determinado período de tempo.

$M$ artinez \& Bosi ${ }^{6}$ afirmam que para uma pesquisa ser considerada qualitativa, ela deve apresentar: a pergunta ou o objetivo da investigação; uma determinada postura teórica ou epistemológica; a correspondente estratégia para a obten ção das informaç̃ões e sua análise.

Como exemplo, quando se procura compreender um determinado fenômeno, tal como a ex- periência do idoso com a saúdebucal ao longo da vida, sendo este o objetivo da pesquisa, pode-se adotar, como estratégia para a obtenção das informações, a gravação de entrevistas em fitas, e sua análise pode se desencadear à luz da Grounded Theory (referencial metodológico). A postura teórica, ou seja, o referencial teórico que irá amparar o estudo dos pesquisadores, neste caso, poderá ser o Interacionismo Simbólico.

Para desenvolver a investigação qualitativa, o pesquisador passa por três fases denominadas por Lüdke ${ }^{7}$ de: exploração, decisão e descoberta. A fase de exploração, ou primeira fase, envolve a seleção e definição do problema, a escolha do local ondeseráfeito o estudo eo estabelecimento de contatos para a entrada no campo. N essa etapa inicial, também se encontram as primeiras observações com a finalidade de conhecer melhor 0 fenômeno eselecionar os aspectos a serem investigados. Esses primeiros questionamentos orientarão na coleta dos dados e na formulação de hipóteses que poderão ser modificadas, à medida que mais dados sejam coletados.

A fase de decisão, ou segunda fase, envolve a busca sistemática dos dados selecionados, como os mais importantes para compreender e interpretar o fenômeno estudado. Os tipos de dados coletados podem mudar durante a investigação, pois as informações colhidas e as teorias emergentes devem ser usadas para dirigir a coleta dos dados.

A fase da descoberta, ou terceira fase, consiste na exploração da realidade, ou seja, na tentativa de encontrar os princí pios subjacentes ao fenômeno estudado edesituar as várias descobertas num contexto mais smplo ${ }^{7}$. Complementam, ainda, queos fatores não se revelam gratuita e diretamente aos olhos do pesquisador, não são passados a ele, e que nem o mesmo os enfrenta desarmado de todos os princípios e pressuposições, ou seja, desprovido de sua visão de mundo. Interrogando os dados, baseado no conhecimento que se tem do assunto, vai se construindo o conhecimento sobre 0 fato pesquisado. N essa fase, o pesquisador desenvolveteorias num processo indutivo detodo o estudo.

\section{A Grounded Theory}

\section{Elucidando a metodologia qualitativa proposta neste estudo}

A Grounded Theory é um método desenvolvido por dois sociólogos: Barney Glaser (Uni- 
versidade de Columbia) e Anselm Strauss (Universidade de Chicago). 0 primeiro, enquanto realizou análises qualitativas, observou a necessidade de realizar comparações entre os dados, a fim deidentificar, desenvolver e relatar conceitos. $O$ segundo foi fortemente influenciado por interacionistas, tais como M ead e Blumer. Segundo Strauss \& Corbin ${ }^{4}$, Strauss contribuiu para o desenvolvimento da Grounded Theory nos seguintes aspectos:

- Necessidade de ir ao campo para descobrir o quê está ocorrendo;

- Relevância da teoria, baseada nos dados, para o desenvolvimento de uma disciplina e como a base da ação social;

. Complexidade e variabilidade do fenômeno e da ação humana;

- Crença que as pessoas são atores, possuindo um papel ativo em resposta às situações problemáticas;

. Compreensão queas pessoasatuam na base do significado;

. Compreensão dequeo significado é: definido e redefinido por meio da interação;

- Sensibilidade para o envolvimento e desdobramento com a natureza dos eventos (processo);

. Consciência da inter-relação entre condições (estrutura), ação (processo) e conseqüências.

Glaser \& Strauss ${ }^{8}$ descreveram esta metodologia com o intuito de estudar modelos fundamentais conhecidos como um processo sociopsicológico básico, capaz de descrever variações na interação ao redor do fenômeno ou problema. Esta abordagem tem suas origens nas Ciências Sociais, especificamente, no I nteracionismo Simbólico da Psicologia Social e da Sociologia. 0 objetivo da Grounded Theory é gerar uma teoria sobre o fenômeno social e psicológico.

Glaser \& Strauss ${ }^{8}$ afirmam que essa metodologia consiste na descoberta e no desenvolvimento de uma teoria a partir das informações obtidas eanal isadas sistemática ecomparativamente. Para eles, a teoria significa uma estratégia para trabaIhar os dados em pesquisa, que proporciona modos de conceituação para descrever e explicar. Estes autores apresentam um método de análise comparativa constante, em que o pesquisador, ao comparar incidente com incidentenos dados, estabelece categorias conceituais que servem para explicar o evento. A teoria, então, é gerada por um processo de indução, no qual categorias analíticas emergem dos dados e são elaboradas conforme $o$ trabalho avança.

\section{Coletando e analisando os dados}

Para a coleta dos dados, o pesquisador pode fazer uso de entrevistas. Chenitz \& Swanson ${ }^{9}$ afirmam que as entrevistas podem ser de dois tipos: estruturadas e não-estruturadas. As primeiras utilizam um modelo de entrevista em queo entrevistador não desvia da seqüência das questões elaboradas. Já as não-estruturadas referem-se a uma entrevista intensa e profunda, sendo o tipo mais comumente usado para coletar dados qualitativos e também se constituem nas entrevistas mais comumente adotadas na Grounded Theory.

Quanto à amostra, Glaser \& Strauss ${ }^{8}$ descrevem-na como amostra teórica, em que o pesquisador decide que dados coletar em seguida, em função da análise que vem realizando. N este sentido, a amostragem adotada não é estatística, mas teórica, uma vez que o número de sujeitos ou situações que devem integrar o estudo é determinado pelo que eles denominaram de saturação teórica, ou seja, quando as informações começam a ser repetidas e dados novos ou adicionais não são mais encontrados. Os autores esclarecem que a amostra teórica é realizada com o objetivo de descobrir categorias e suas propriedades, e também sugerir inter-relações dentro da teoria. No que se refereà amostra estatística, ela é real izada a fim de obter acurada evidência na distribuição de pessoas entre categorias a serem estudadas para descrições e verificações de fenômenos. A amostra térica tem o objetivo de mostrar eventos que sejam indicativos de categorias enão de pessoas.

Prosseguindo acerca deste tipo de amostra adotada em pesquisas qualitativas, Strauss \& Corbin ${ }^{4}$ descrevem-na como sendo aquela em que os dados devem ser coletados até que cada categoria esteja saturada, ou seja, até que: (a) nenhum dado relevante emirja; (b) a categoria esteja bem desenvolvida em termos de suas propriedades e dimensões, demonstrando variação; (c) configure 0 relacionamento entre as categorias. $M$ ayan ${ }^{10}$ também afirma queospesquisadoresnão devem mais coletar os dados quando todos os dados das categorias estejam saturados e isto ocorre quando: a) nenhum dado novo ou relevante emirja; b) todos os caminhos tenham sido seguidos; c) quando a história ou a teoria está completa. Esta autora ainda afirma que a saturação é obtida no momento em que a categoria desenvolvida está densa, em variação e processo, e as relações entre categorias estão bem estabelecidas e validadas.

Vale ressaltar que propriedades são as características de uma categoria, o que define e dá sig- 
nificado às mesmas e quando estas variam, podemos dizer que são categorias que pertencem a outras dimensões diferentes e, portanto, permitem imprimir variações à teoria ${ }^{4}$.

A fim de exemplificar a utilização da Grounded Theory na O dontologia, trazemos o exemplo, contido no Quadro 1, de parte de uma pesquisa que visou: compreender a experiência do idoso com a saúde bucal ao longo da vida e desenvolver evalidar um modelo teórico representativo dessa experiência ${ }^{11}$. A entrevista utilizada foi não-estruturada, do tipo focalizada, tendo a seguinte pergunta norteadora: - Como tem sido a sua experiência com a saúde bucal ao longo da vida? Para tanto, a coleta de dados foi realizada após o parecer favorável do Comitê de Ética em Pesquisa, da Faculdade de Medicina de Botucatu U NESP e a autorização dos atores que participaram deste estudo, conforme Resolução №. 196, de 10 de outubro de 1996, queaprovou as diretrizes e normas que regulamentam as pesquisas envolvendo seres humanos ${ }^{12}$.

A pós a entrevista, o método da Grounded Theory preconiza que a transcrição na íntegra das gravações seja realizada. A pós esta transcrição, a próxima etapa consiste na descoberta de categorias, realizando o que denominamos de codificação aberta. Dessa forma, o passo inicial, uma vez redigido o texto da observação ou entrevista, consiste em quebrar os dados em pequenos pedaços, em que cada um deles representa um incidente específico ou fato. Para isso, os dados são analisados linha por linha e parágrafo por parágrafo, buscando incidentes e fatos. Cada incidenteé codificado como um conceito ou abstração do dado. Esta etapa está exemplificada no Q uadro 2, o qual ilustra como se iniciou a entrevista, com a pergunta norteadora, e como é realizada a codificação aberta.

A Figura 1 representa um importante esquema a ser seguido na elaboração de estudos que utilizam esta abordagem qualitativa, em que: os fenômenos são formados por temas, que por sua vez são formados por categorias, e estas são congregadas por subcategorias compostas por elementos. N ão necessariamente emergem todos estes componentes. Às vezes, por exemplo, uma categoria pode não congregar subcategorias.

Fenômenos: são importantes idéias analíticas que emergem dos dados. Eles descrevem os problemas e assuntos do estudo.

Categorias: são conceitos derivados dos dados que representam o fenômeno.

Subcategorias: especificam uma categoria, denotando informações quanto aos seguintes as-
Quadro 1. Trecho da entrevista não-estruturada, do tipo focalizada.

Pergunta: Como tem sido a sua experiência com a saúde bucal ao longo da vida?

Resposta: Bom, na minha primeira infância, eu tive orientação de meu pai e de minha mãe, que sempre se preocuparam em que eu e meu irmão escovássemos os dentes, após as refeições, antes de deitar. E aos sete anos eu comecei o curso primário, que era 0 grupo escolar, né, que chamavam naquela época, que tinha um dentista de, ou meio período, ou tempo integral, mas eu sei que todos os alunos do grupo escolar passavam pelo consultório do dentista e se fosse necessário algum tratamento era feito lá mesmo. Então nós tínhamos assistência odontológica nos quatro anos primários.

Quadro 2. Descobrindo categorias, por meio da codificação aberta

\begin{tabular}{|c|c|}
\hline $\begin{array}{l}\text { TRECHO DA } \\
\text { ENTREVISTA }\end{array}$ & CÓDIGOS \\
\hline $\begin{array}{l}\text { Bom, na minha primeira } \\
\text { infância, eu tive orienta- } \\
\text { ção de meu pai e de mi- } \\
\text { nha mãe, que sempre se } \\
\text { preocuparam em que eu } \\
\text { emeu irmão escovássemos } \\
\text { os dentes, após as refei- } \\
\text { ções, antes de deitar. }\end{array}$ & $\begin{array}{l}\text { Tendo orientação dos } \\
\text { paisna primeira infância. } \\
\text { Pais se preocupando que } \\
\text { os filhos escovassem os } \\
\text { dentes após as refeiçõese } \\
\text { antes de deitar. }\end{array}$ \\
\hline
\end{tabular}

Figura 1. Esquema representativo dos componentes do processo da Grounded Theory

$$
\begin{gathered}
\text { FENOMMENOS } \\
\uparrow \uparrow \uparrow \\
\text { TEMAS } \\
\uparrow \uparrow \uparrow \\
\text { CATEGORIAS } \\
\nwarrow \uparrow \nearrow \\
\text { SUBCATEGORIAS } \\
\nwarrow \uparrow \nearrow \\
\text { ELEMENTOS }
\end{gathered}
$$

pectos: quando, onde, porque e como um fenômeno é provável de ocorrer. 
Outros exemplos, contidos nos quadros 3 e 4 , serão apresentados, no intuito de entendermos mais acerca da realização da descoberta do processo ilustrado na Figura 1. 0 Quadro 3 representa a transcrição de parte das entrevistas realizadas com os sujeitos 11, 12, 13 e 14 e o Q uadro 4 consistenos códigos extraídos destas transcrições.

Quadro 3. Transcrição de parte das entrevistas com os sujeitos 11, 12, 13 e 14.

[...] Ah, eu sei que uma vez, era um sítio grande que o meu pai tinha, então o dentista queria por uma capinha de ouro no dente. U sava aquele tempo, né? E eu sumi pro cafezal, de medo. E eu demorei pra vim, demorei. Enquanto isso, ele tratou de todos os outros. Mas depois ele me pegou. Aí ele pôs. Não tinha dente estragado. Não era estragado 0 dente. M as ele quis pôr uma capinha no lado[...] (11.2)

[...] Sempre a gente achava que dentista era sofrimento, ia sentir dor, sei lá. Acho que é uma coisa muito palpável naquela época, o medo do dentista. Toda criança tinha[...] N ão tinha essa maneira de [...] hoje tem dentista especializado em criança, que usa da psicologia, que faz todo um trabalho pra criança não ter medo, se sentir à vontade e não temer 0 dentista. Não era assim antigamente. (12.3)

Tenho horror. Não me fale em dentista[...] Pelo problema da anestesia[...] Era uma agulha grossa, menina. E dava duas, três anestesia no mesmo local. Eu tenho pavor disso. A gente morria de medo do abençoado motor[...] Ai! M eu Deus! Mas também tive muita hemorragia com negócio de dente. M uita hemorragia. Sofri bastante do dentista ficar a noite inteira comigo porque não parava 0 sangue. $M$ as ele foi o seguinte. Coitadinho, já morreu. Ele não deu ponto, sabe? Então, aquilo ficou saindo, saindo, saindo[...] Extraía e não costurava. Ficava aquele bocão. Aquele machucadão aberto[...] (13.1)

Eu me lembro que eu tive uma época que eu tive obturação pra fazer, então eu ia, ficava com medo, tinha medo do motorzinho. Saía, chegava no colégio a irmã olhava e via que eu não tinha passado pelo dentista, aí me levava. (14.2)
Q uadro 4. Codificação aberta de parte das entrevistas com os sujeitos 11, 12, 13 e 14 .

- Sendo um sítio grandequeo pai delatinha(11.2.2)

- Dentista querendo colocar capinha de ouro no dente dela (11.2.2)

- U sando capinha de ouro aquele tempo (11.2.2)

- Sumindo pro cafezal de medo (11.2.2)

- Demorando para voltar do cafezal (11.2.2)

- Dentista tratando de todos os outros (11.2.2)

- Dentista pegando ela depois (11.2.2)

- Dentista colocando a capinha de ouro no dente dela (11.2.2)

- Não tendo dente estragado (11.2.2)

- Achando sempre que dentista era sofrimento (12.3.2)

- Achando sempre que ia sentir dor no dentista (12.3.2)

- Achando que o medo do dentista era uma coisa muito palpável naquela época (12.3.2)

- Tendo toda criança medo de dentista naquela época (12.3.2)

- Não tendo naquela época a maneira que os dentistas têm hoje de atender (12.3.2)

- Tendo hoje dentista especializado em criança, usando da psicologia (12.3.2)

- Dentista hoje fazendo todo um trabalho para a criança não ter medo, se sentir à vontade e não temer o dentista (12.3.2)

- Não sendo assim antigamente (12.3.2)

- Tendo horror de dentista (13.1.1)

- Tendo medo do dentista por causa da anestesia (13.1.1)

- Sendo a anestesia uma agulha grossa daquela época (13.2.1)

- Dando duas, três anestesia no mesmo local (13.2.1)

- Tendo pavor de anestesia (13.2.1)

- Morrendo de medo do motor (13.2.1)

- Tendo medo do dentista porque teve muita hemorragia (13.1.1)

- Sofrendo bastante naquele tempo e ficando o dentista a noite toda com ela porque não parava o sangue (13.1.1)

- Dentista arrancando o dente e não dando ponto aquela época (13.1.1)

- Extraindo o dente e não costurando aquela época (13.1.1)

- Ficando aquele bocão e aquele machucadão aberto depois que extraía o dente aquela época (13.1.1)

- Lembrando que teve uma época que tinha obturação para fazer (14.2.1)

- Tendo medo do motorzinho (14.2.1)

- Ficando com medo do dentista por causa do motorzinho (14.2.1)

- Freira vendo que ela não tinha passado no dentista de medo, quando chegava no colégio interno (14.2.1)

- Freira a levando no dentista (14.2.1) 
Com estes códigos, contidos no Quadro 4, podemos descobrir os componentes que congregam a metodologia qual itativa em questão. Nesse caso, como parte de uma experiência maior, trazemos, no Quadro 5, as subcategorias e elementos que compuseram estes códigos apresentados, nomeados e agrupados da seguinte forma:

Quadro 5. Sentindo medo do cirurgião-dentista naquele tempo: elementos.

\footnotetext{
Sentindo medo do cirurgião-dentista naquele tempo (subcategoria)

- Sendo o medo do dentista uma coisa muito pal pável naquela época (12.3.2)

- Tendo toda criança medo de dentista (12.3.2)

- Sumindo para o cafezal de medo (11.2. 2 )

Temendo os procedimentos realizados pelo cirurgião-dentista naquela época (elemento)

- Achando sempre que dentista era sofrimento (12.3.2)

- Achando sempre que ia sentir dor no dentista

(12.3.2)

- Tendo medo do dentista por causa da anestesia (13.1.1)

- Tendo medo do dentista porque teve muita hemorragia (13.1.1)

- Sofrendo bastante naquele tempo e ficando o dentista a noite toda com ela porque não parava o sangue (13.1.1)

- Dentista arrancando o dente e não dando ponto aquela época (13.1.1)

- Extraindo o dente e não costurando aquela época (13.1.1)

- Ficando aquele bocão e aquele machucadão aberto depois que extraía o dente aquela época (13.1.1)

- Sendo a anestesia uma agulha grossa daquela época (13.2.1)

- Dando duas, três anestesia no mesmo local (13.2.1)

- Tendo pavor de anestesia (13.2.1)

- Tendo medo do motor (13.2.1)

- Ficando com medo do dentista por causa do motorzinho (14.2.1)

- Freira vendo que ela não tinha passado no dentista demedo, quando chegava no colégio interno (14.2.1)

- Dentista querendo colocar capinha de ouro no dente dela (11.2.2)
}

Não sendo a Psicologia uma ferramenta no atendimento odontológico naquela época (elemento)

- Não tendo naquela época a maneira que os dentistas têm hoje de atender (12.3.2)

- Tendo hoje dentista especializado em criança, usando da psicologia (12.3.2)

- Dentista hoje fazendo todo um trabalho para a criança não ter medo, se sentir à vontade e não temer o dentista (12.3.2)
Ou seja, percorremos a seguinte etapa:

. Ligando categorias: Uma vez as categorias identificadas, é efetuada nova comparação, desta vez entre categorias, o que determina uma meIhor estruturação do conceito. Destemodo, ocorre um processo de redução das categorias, em que, pela comparação, é identificada a idéia que meIhor explica o fenômeno daquele grupo de categorias. São, então, identificadas as categorias e seus componentes (ou subcategorias).

O número entreparêntese(11.2.1), por exemplo, é o número que identifica o sujeito entrevistado (11) , a página (2) em que se localiza a transcrição da entrevista real izada com este sujeito ea página (1) em que se encontram os códigos obtidos após a codificação aberta, respectivamente, facilitando as etapas da metodologia, sem haver a identificação dos sujeitos entrevistados.

D ando continuidadeà análise dos dados, percorremos a seguinte etapa:

- Desenvolvimento de memorandos: o processo de construção da teoria implica o registro do processo analítico desdeo seu início, demodo quese pode perceber o desenvolvimento do conceito, quase que passo a passo. N este sentido, após a codificação inicial das primeiras observações, todas as idéias que surgem em função da leitura e das próprias observações passam a ser registradas.

D esta forma, baseando-se nos códigos extraídos das entrevistas, realizamos a conceituação. A conceituação é uma abstração dos códigos, na qual se deve evitar ao máximo a interpretação além do que estes códigos nos revelam. Assim, num constante processo de indução e comparação, o conceito abstraído de partedestas entrevistas dos sujeitos 11, 12, 13 e 14 foi o que se segue:

Sentindo medo do cirurgião-dentista naquele tempo

É o momento da experiência que consistia numa limitação do acesso ao serviço odontológico, porque o medo era uma variável que ajudava a afugentar as pessoas do tratamento dentário. 0 medo de hoje, relatado pelosidosos desta pesquisa, é concebido como decorrente das práticas empregadas pelo cirurgião-dentista (CD) para atender os pacientes.

O profissional era associado ao sentimento dedor esofrimento. Dificilmente uma criança não tinha medo do CD naquela época. Estemedo também era decorrente da anestesia usada, possuindo uma agulha de calibre grosso, que amedrontava as pessoas; da caneta de alta rotação que causava medo às crianças; da não sutura após a extração dentária naquela época e também devi- 
do aos procedimentos quea criança desconhecia. A pós a extração, o paciente sofria as conseqüências de uma hemorragia, que demorava algum tempo para ser, fisiologicamente, estancada. Estes fatores contribuíam para que as pessoas sentissem medo naquela época.

Não era hábito de o CD aplicar todo um conhecimento baseado na Psicologia previamentee duranteo atendimento ao paciente. $\mathrm{H}$ ojeas experiências evidenciam quehá as especialidades odontológicas, tais como a O dontopediatria. Esta, trabalhando com o conhecimento apreendido pela Psicologia, também contribui para o desaparecimento do medo da criança quanto ao tratamento odontológico.

Esta subcategoria é composta por dois elementos: - temendo os procedimentos realizados pelo cirurgião-dentista naquela época; - não sendo a Psicologia uma ferramenta no atendimento odontológico naquela época.

O último passo é:

Identificação do processo: uma vez as categorias e seus componentes identificados, elas são ordenadas demaneira aidentificar uma queécentral, ou melhor, aquela categoria com a qual todas se relacionam. Para chegar a ela, são elaborados esquemas e aplicados aos dados (novo retorno aos dados, de modo a verificar qual deles parecemelhor expressar as experiências dos idosos, em termos conceituais).

\section{Descobrindo a categoria central e validando o modelo teórico representativo}

Analisando os dados com a metodologia em questão, emerge a essência da representação do estudo empreendido, convencionalmente denominado de categoria central. Para se chegar a ela, realizamos a inter-relação dos fenômenos apreendidos no estudo, a fim de compará-los e analisá-los, para compreender a interação entreosseus componentes.

0 método da Grounded Theory preconiza o desenvolvimento deum modelo teórico represen- tativo que ilustre a categoria central. Uma vez seguido os passos do referencial metodológico e descoberto o processo que esteja sendo estudado, é necessário validar o modelo teórico. Esta validação é realizada de acordo com as recomendações de Strauss \& Corbin ${ }^{4}$. Segundo os autores, a teoria emerge dos dados e representa uma abstração; portanto, é importante determinar se 0 model o teórico esquematizado não foi omisso ou está representado além dos significados dos dados. Um dos caminhos utilizados para validar o model o teórico éo de retornar aos dados e comparar o modelo com os dados brutos, realizando um tipo de análise comparativa. Estemodelo teórico tem que ser capaz de explicar a maioria dos casos. Outra forma é contar a história para os sujeitos participantes do estudo ou pedir que eles a leiam e percebam se a mesma está adequada. É claro que a história não estará adequada em todos os aspectos de cada caso, em virtude de a história ser uma redução dos dados, mas, de forma geral, os sujeitos deverão se reconhecer na história lida.

\section{Consideraçõesfinais}

Os pesquisadores, na área da saúde, vêm se apropriando, cada vez mais, de metodologias qualitativas, desenvolvidas nas Ciências Humanas, para responder as questões das pesquisas.

A utilização da Grounded Theory na área de saúde bucal poderá contribuir para acrescentar conhecimento aos assuntos que ainda não foram explorados qualitativamente ou que necessitam adquirir contribuições originais.

Esta metodologia, permitindo o desenvolvimento de modelos teóricos explicativos dos fenômenos em estudo, é de enorme contribuição para os profissionais de saúde e para as questões norteadoras das Políticas de Saúde, inclusive as de saúde bucal, possibilitando, dentre outros benefícios, a melhoria da qualidade de vida do ser humano. 


\section{Colaboradores}

LSN ico foi responsável pela idealização do artigo, participando de todas as etapas do trabaIho, o que inclui, também, a coleta dos dados. SCM Bocchi foi responsável pela orientação quanto à metodologia qualitativa empregada neste trabalho (Grounded Theory), tendo fundamental participação na análise dos dados, na redação e revisão do artigo. T Ruiz foi responsável pela orientação da pesquisa e revisão crítica do artigo. RS M oreira auxiliou na revisão e formatação do artigo.

\section{Referências}

1. Charon JM. Symbolic interactionism: an introduction, an interpretation, an integration. N ew Jersey: Prentice Hall; 1989.

2. Bazilli C, Renteria E, Duarte JC, Franciscatti KVS, Andrade LF, Rala LA. Interacionismo simbólico e a teoria dos papéis: uma aproximação para a psicologia social. São Paulo: Educ; 1998.

3. Littlejonh SW. Fundamentos teóricos da comunicação humana. Rio de Janeiro: Guanabara; 1986.

4. Strauss A, Corbin J, organizadores. Basics of qualitative research: techniques and procedures for developing grounded theory. London: SAGE Publications; 1998.

5. Field PA, M orse JM, organizadores. Nursing research: the application of qualitative approaches. M aryland: Aspen Publishers; 1985.

6. Martínez FJM, Bosi M LM . N otas para um debate. In: Bosi M LM, M ercado FM, organizadores. Pesquisa qualitativa de serviços de saúde. Petrópoles: Vozes; 2004. p. 33-71.

7. Lüdke $M$, André M. Pesquisa em educação: abordagens qualitativas. São Paulo: EPU; 1986.

8. Glaser BG, Strauss AL, organizadores. The discovery of grounded theory. New York: Aldine Publishing Company; 1967.

9. Chenitz WC, Swanson JM, organizadores. From practice to grounded theory. Canada: Addison-Wesley Publishing Company; 1986.

10. Mayan MJM. An introduction to qualitative methods: a training module for students and professionals. Edmonton, Alberta: International for Qualitative $\mathrm{Me}$ thodology; 2001.

11. Nico LS. Do passado ao futuro: a experiência do idoso com a saúde bucal [dissertação]. Botucatu (SP): Universidade Estadual Paulista; 2006.

12. Universidade Estadual Paulista. Faculdade de M edicina de Botucatu. Comitê de Ética em Pesquisa. Diretrizes e normas regulamentadoras de pesquisa envolvendo seres humanos. Botucatu: Tipomic; 1997.

Artigo apresentado em 09/12/2005

Aprovado em 11/08/2006

Versão final apresentada em 24/11/2006 